Estudios sobre armas antiguas, arte militar y vida cultural en oriente y occidente XXX (2010), pp. 137-154 ISSN : 0436-029X

doi: 10.3989/gladius.2010.0007

\title{
SOBRE ALGUNOS TEXTOS CLÁSICOS REFERENTES A LA CABALLERÍA DE LOS CELTÍBEROS Y AL SIMBOLISMO DE SUSARMAS
}

\author{
ON SOME LITERARY SOURCES REFERRING TO CELTIBERIAN CAVALRY \\ AND THE SIMBOLISM OF WEAPONS
}

POR

Manuel Salinas de Frías*

\section{Resumen - A bstract - Résumé}

Algunos textos clásicos (Str. 3.3.6 y 4.15; Pol. Fr, 95 y Diod. 3.3.5) muestran la existencia de dos clases de combatientes en los ejércitos celtibéricos: una minoría armada con la panoplia completa, que combatía a caballo, y una mayoría equi pada ligeramente. Estas diferencias de armamento reflejan la diferencia social entre la aristocracia y el resto de la población. La comparación con otras aristocracias ecuestres, principalmente la griega y la romana, muestra que la aristocracia celtibérica era principal mente una infantería montada cuyas armas constituían un símbolo de su estatus social. En particular, podemos detectar un simbolismo asociado a la espada.

M any classical texts (Str. 3.3.6 y 4.15; Pol. Fr, 95 y Diod. 3.3.5) show the existence of two kinds of fighters in the celtiberic armies: the few armed with complete weapons, fighting on horseback, and the majority lightly equipped. These differences of the weapons reveal the social difference between the aristocracy and the remains of the population. The comparison with other equestrian aristocracies, mainly the Greek and the R oman aristocracy, shows that the celtiberic aristocracy was mainly a mounted infantry whose weapons were a symbol of her social status. Particularly, we can detect a symbolism associated to the sword.

Un certain nombre de textes d' auteurs anciens (Str. 3.3.6 y 4.15; Pol. Fr, 95 y Diod. 3.3.5) attestent l' existence de deux catégories de combattants dans les armées celtibères : une minorité dotée de la panoplie complète et combattant à cheval ; une majorité équipée à la légère. Ces différences dans l' armement reflètent la différenciation sociale entre l'aristocratie et le reste de la population. L a comparaison avec d' autres aristocraties équestres, notamment celles des sociétés grecque et romaine, montre que l'aristocratie celtibère était principal ement une infanterie montée dont les armes constituaient le symbole de son statut social. On peut en particulier mettre en évidence un symbolisme associé à l'épée.

Palabras Clave - Keywords - Mots clés

Guerra antigua; celtíberos; armamento.

Ancient warfare; Celtiberians; weapons.

Guerre antique; Celtibères; armement.

* Departamento de Prehistoria, Historia Antigua y Arqueología, Facultad de Geografía e Historia, Universidad de Salamanca, C/ Cervantes s.n.- 37002 Salamanca. Email: vafio@ usal.es. Proyecto de Investigación de la JCyL: SA 003A 10-1. 
Los autores clásicos proporcionan información sobre el armamento de los pueblos prerromanos cuya correlación con los datos arqueológicos es, sin embargo, muy difícil. L a dinámica de guerra que prevaleció en el contacto entre la sociedad romana y los pueblos indígenas sin duda debió influir en el interés por el armamento y su descripción que demuestran la mayor parte de nuestras fuentes. De ello constituyen un buen ejemplo las descripciones sobre la metalurgia indígena y la fabricación de armas, especialmente sobre la espada celtibérica o gladius hispaniensis. A demás, la organización timocrática de las sociedades clásicas, a la que estaban habituados estos autores, ha podido influir en la presentación que hacen las fuentes literarias, tanto de la sociedad como de los ejércitos indígenas y su armamento, pero no por ello hay que excluir una organización indígena semejante, en la cual se daría un correlato entre la posición social y el armamento y la simbología asociada a él (Salinas, 1998).

Tenemos dos loci classici, ambos de Estrabón, que dicen lo siguiente:

«Se dice de los lusitanos que son hábiles en emboscadas y exploraciones, siendo ágiles, ligeros y capaces de salir de peligros. Dicen que ellos usan una pequeña rodela (aspidíon) que tiene un diámetro de dos pies y es cóncava por delante, y se maneja por correas, no teniendo ni abrazadera ni asa. A demás Ilevan puñal (paraxíphis) o sable (kópis). La mayor parte tiene corazas de lino (linothôrakes) y sólo unos pocos corazas de malla (alysidôtois) y un casco con tres penachos (trilophiais), mientras los demás usan cascos de nervios. Los infantes usan también grebas y cada uno lleva varias jabalinas (akóntia). A Igunos tienen lanzas (dórati) para estoque con puntas de bronce.» (3.3.6).

Casi todos los iberos, por así decir, combaten como peltastas, armados a la ligera (koûphoi katà ton hoplísmon) por su bandolerismo, como dijimos de los lusitanos, usan jabalina (akontíon), honda (sphendonê) y puñal (machaíra). Con los infantes está mezclada también la caballería, siendo los caballos adiestrados en subir sierras y arrodillarse con facilidad, cuando esto hace falta y se les manda.» (3.4.15, traducción de FHA VI).

L os dos textos establecen una diferenciación de los combatientes en función de su armamento que es, simultáneamente, una diferenciación militar y social. A demás de la existencia de infantes mejor armados (una minoría) o peor armados (la mayoría), existe una caballería, que parecen ser los pocos (spanioi) que llevan corazas de malla y cascos con penachos. Distintos textos clásicos referentes a la cabal lería celtibérica permiten conocer la correspondencia entre su organización militar y táctica y su organización social. Lo que parece deducirse de ellos, como veremos, es que la fuerza militar más importante de las ciudades-estado celtibéricas era un grupo armado con casco, coraza de malla, grebas y escudo como armas defensivas, y lanza y espada o puñal como armas ofensivas. Esta fuerza, más que una caballería propiamente dicha, era una infantería montada, reclutada entre la aristocracia de las ciudades (Salinas, 1998; Quesada, 1998: 171-173).

Polibio, fr. 95, dice:

«Esto tienen de particular los celtíberos en la guerra: cuando ven que sus infantes ceden, descabalgan y dejan los caballos dispuestos en formación; al efecto disponen unos pequeños clavos al extremo de las riendas, los que clavan en el suelo enseñando a los caballos a no moverse de la fila hasta que ellos vuelven y arrancan los clavos. L os celtíberos sobresalen en mucho entre los demás pueblos en la fabricación de espadas. Sus espadas tienen en efecto una punta resistente y un tajo cortante por los dos lados. Por lo cual los romanos desde los tiempos de A níbal abandonaron las espadas de sus antepasados cambiándolas por las de los iberos. Pero si pudieron imitar la forma, nunca lograron al canzar la calidad del hierro y la perfección de la factura» (traducción de FHA IV, Barcelona 1937, 255). 
A esto mismo debe referirse Diodoro (5.33.5) cuando dice: «(los celtíberos) son capaces de luchar de dos maneras, pues tan pronto se ven vencidos luchando a caballo, saltando también a tierra y adoptando la formación de los infantes combaten admirablemente». El texto de Estrabón antes citado (3.4.15) refiere la misma práctica. I gualmente, narrando el último combate de Indíbil contra los romanos, Livio hace referencia a que los jinetes de los ilergetes echaron pie a tierra en lo más encarnizado del combate contra los romanos ${ }^{1}$. O tros testimonios parecen referirse a una práctica distinta, atestiguada por Estrabón 3.4.18, cuando dice: «Tampoco es particular de los iberos que dos hombres vayan montados en un caballo, y que uno de ellos en el combate luche a pie». A unque cuando dice esto se refiere a los habitantes de Iberia en general, sin embargo lo hace en el transcurso de la descripción de Celtiberia; y, aunque diferente de la táctica mencionada, como veremos más adelante tiene relación con ella desde el punto de vista social.

La conexión entre caballería y calificación social es un hecho casi general del mundo antiguo y los paralelos mejor conocidos los podemos encontrar en la Grecia y la Roma arcaicas.

En G recia la caballería de los siglos X-V II a.C. fue el grupo militar que representaba en el campo de batalla a la aristocracia. Evidentemente, en este hecho influía el coste de mantenimiento de varios caballos, que no estaba al alcance de la mayoría de los ciudadanos. En la A tenas presoloniana el término hippeis, junto con el de eupatridai, se refieren a la clase más al ta (A rist. Pol. 1297b). En la Esparta clásica, en tantos aspectos arcaizante, el término hippeis indicaba un cuerpo de infantería de élite que rodeaba a los reyes en la batalla (L azenby, 1985: 7-14), lo que es un buen indicio de la correlación entre el concepto de jinete y de miembro de la aristocracia. En Calcis los aristócratas recibían el término de hippobatai, es decir, «conductores de caballos». No es necesario remontarse a Homero, cuyos héroes desmontan del carro antes de acometerse con las lanzas, para constatar que la caballería primitiva griega era una tropa de infantes montados. Distintos testimonios, especial mente de vasos pintados, atestiguan que durante el periodo geométrico tardío y en época posterior los caballos se utilizaban para transportar a guerreros pesadamente armados que desmontaban para la batalla y que eran acompañados por un escudero desarmado 0 armado muy escasamente, quien sujetaba las riendas de los caballos durante el combate (figs. 1, 2 y 3). A sí, sobre un vaso corintio de finales del siglo VII a.C., se ve que el hoplita desmontado aparece rotulado como hippobatas, mientras que el escudero que monta otro caballo y retiene el del combatiente recibe el nombre de hippostrophos. Un vaso de estilo protocorintio, aproximadamente un siglo anterior representa una escena parecida (Greenhalgh 1973, resume los testimonios de manera exhaustiva: cap. III «The Homeric hippies», esp. pp. 57-62, donde da apoyo arqueológico a la tesis de Helbig, 1904: 157-sq.). La generalización de la falange hoplita no implicó la desaparición inmediata de la infantería montada: Ios hoplitas más acomodados podían disfrutar de la ventaja de acudir a sus líneas montados, y por consiguiente con las fuerzas más frescas, 0 en caso de derrota huir más rápidamente mediante los caballos. Es esto lo que se representa en un vaso ático de figuras negras, de hacia 575-550 a.C., en que se observan hoplitas desmontando para unirse a la falange (G reenhalgh, 1973: 112, fig. 56).

Pero quizás los mejores paral el os con la táctica ejecutada por la caballería celtibérica los encontramos en noticias sobre la guerra en la R oma arcaica. Durante la batalla del lago R egilo (499 a.C.), el dictador A . Postumio ordenó a la caballería desmontar y ocupar la primera línea, cuando ya la infantería cedía ante el empuje de los latinos (L iv. 2.20). En la batalla del A Igido

1 Liv. 29.2.13:... itaque omissa pugna equestri ad pedes Hispani descenderunt... non sustinuissent tam infestum impetum barbari, ni regulus ipse Indibilis cum equitibus ad pedes degressis ante prima signa peditum se obiecissent. Ibi aliquamdiu atrox pugna stetit, tandem, postquam ii qui circa regem seminecem restantem, deinde pilo terrae adfixum pugnabant, obruti telis occubuerunt, tum fuga passim coepta. 


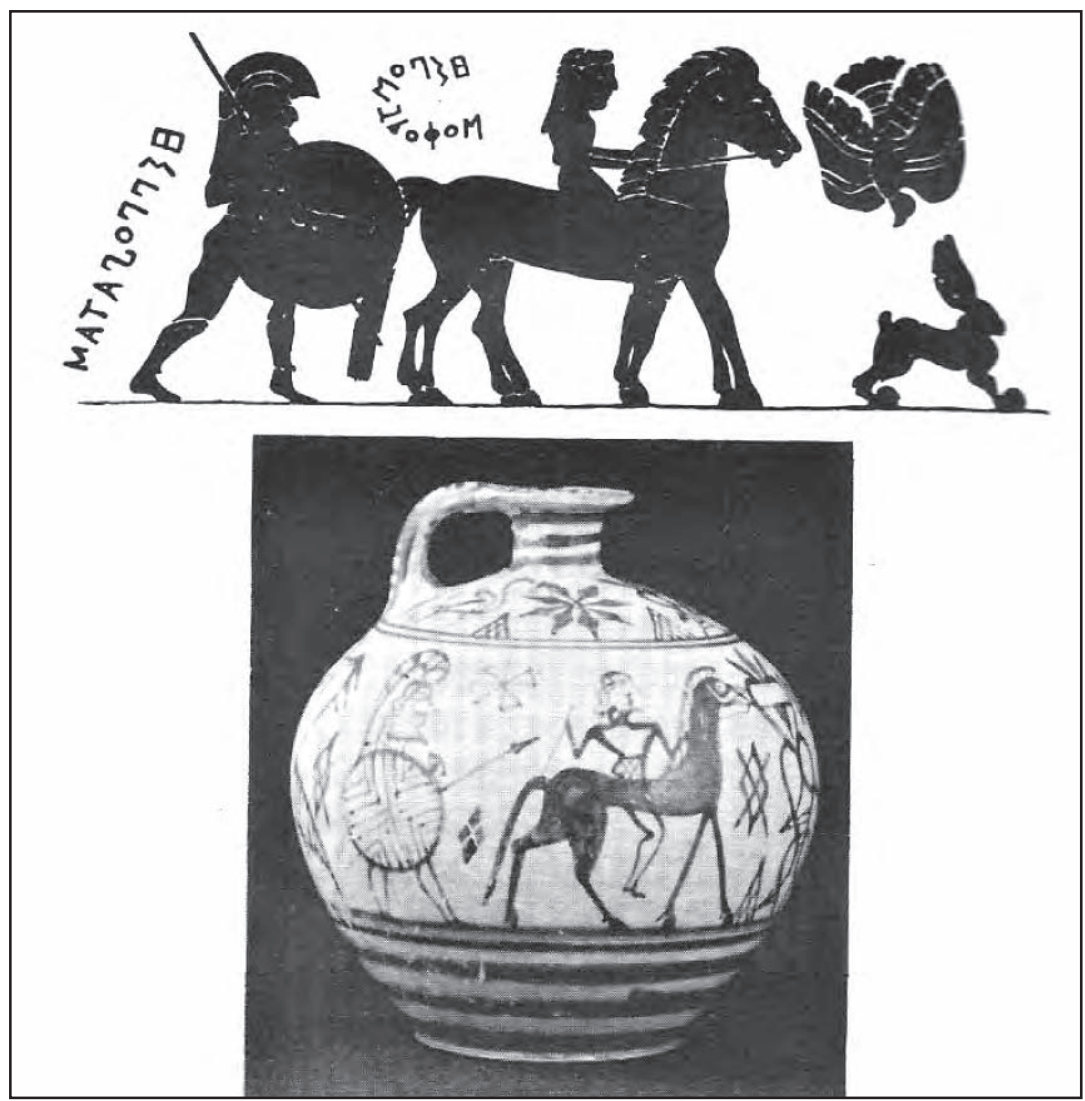

Figura 1. Imágenes de dos vasos protocorintios con representaciones de hoplitas (hippobatas) acompañados de escuderos a caballo (hippostrophos) que retienen también el caballo del guerrero (según Greenhalgh, 1973).

(449 a.C.), la caballería también desmontó para evitar que el ala izquierda de los romanos fuese arrollada por los sabinos (L iv. 3.62). Durante la guerra contra los volscos, en el consulado de C. Sempronio A tratino y Q. Fabio V ibulano (423 a.C.), la caballería dirigida por el decurión Sexto Tempanio desmontó y evitó el desastre de la infantería (L iv. 4.38). Otras ocasiones en que se menciona esta misma maniobra de la caballería son los años 381 a.C., siendo cónsules M. Furio y M. Camilo, también en guerra contra los volscos (Liv. 4.24.10); 362 a.C., en la guerra contra los hérnicos, siendo dictador un Servilio (Liv. 7.7.7-8); en el 315 a.C., bajo la dictadura de Q. Fabio, en la guerra contra los samnitas (Liv. 9.22.10), y en el 310 a.C., bajo la dictadura de L. Papirio, siendo éste el último hecho conocido de este tipo, durante la batalla del lago Vadimón contra los etruscos (Liv. 9.39.8).

A unque todos estos datos se refieren al periodo de la república primitiva, es decir, a aqueIla parte de la historia de Livio cuyos datos parecen menos fiables, y aunque ciertamente la manera de describir los combates en gran medida es ornamental y retórica, sin embargo Tito Livio, a través de sus fuentes, parece guardar el recuerdo de una forma de combatir de la caballería romana que habría desaparecido con la organización manipular del ejército y, en relación con ella, con la depreciación estratégica de los caballeros romanos. Esta forma de combatir concuerda con la interpretación general mente admitida de que la primitiva caballería romana era más bien una infantería montada, diferenciada del resto del ejército sobre todo por 


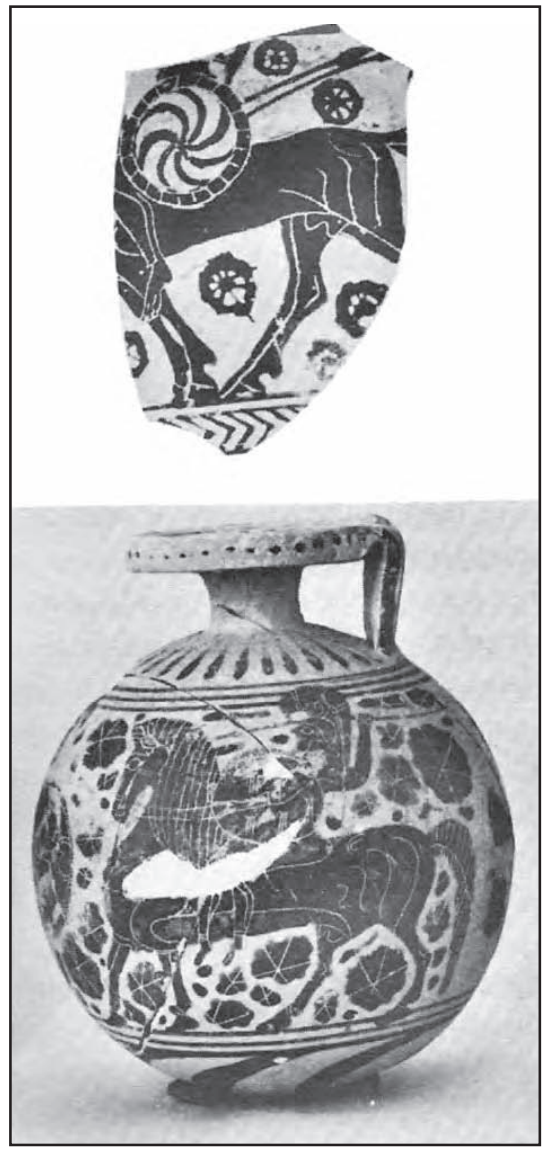

Figura 2. Representaciones de vasos corintios con imágenes de hoplitas combatiendo desde el caballo (según Greenhalg, 1973).

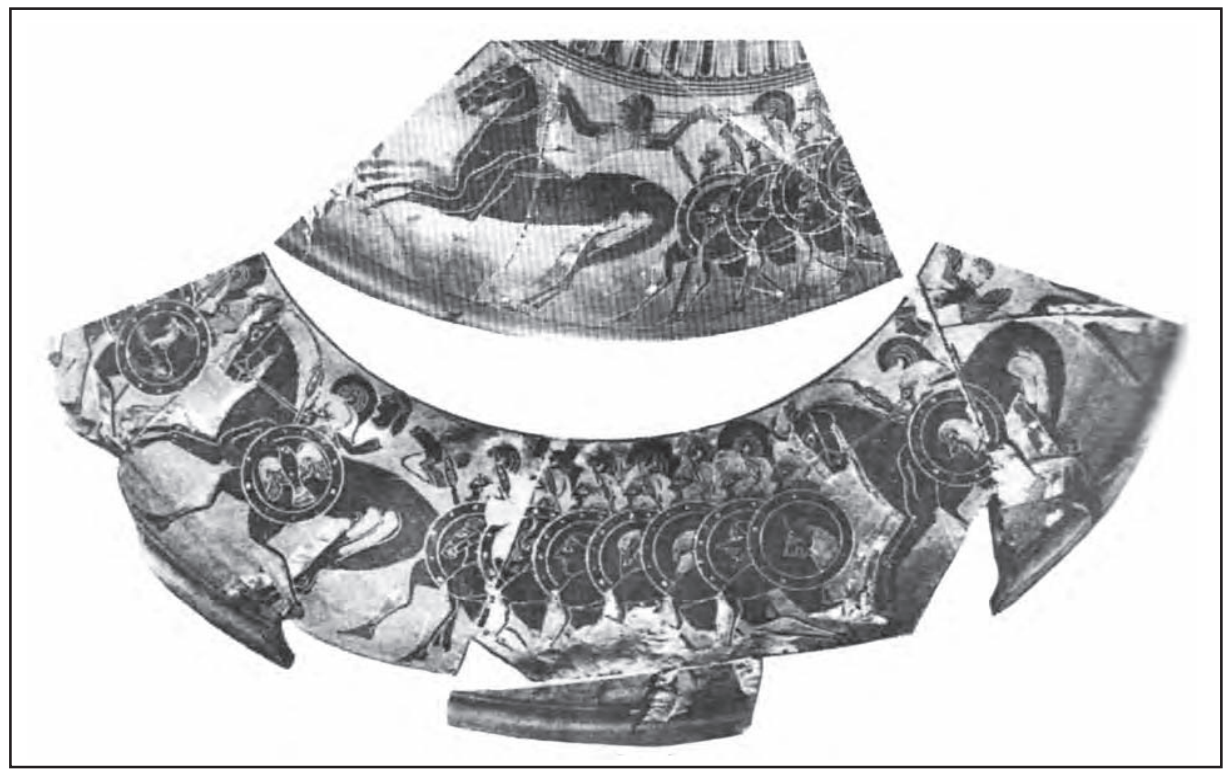

Figura 3. Vaso ático de figuras negras que muestra a hoplitas desmontando para unirse a la falange (según Greenhalgh, 1973). 
la movilidad que le daba el uso del caballo, de lo que derivaría el primitivo nombre de celeres, y no el posterior de equites. Desde el punto de vista económico y social, esta tropa montada era una tropa de élite cuyos miembros se reclutaban entre los más ricos de la ciudad, capaces de mantener un caballo, cuyas dieciocho centurias se superponían, en el ordenamiento civil, a las de la primera clase serviana y eran, como signo de distinción, las que votaban en primer lugar, Ilamadas por ello centuriae procum. Sus distintivos externos, phalerae, calceus y clauus, habrían dado origen al atuendo senatorial (cabría plantearse entre los hispanos la existencia de distintivos semejantes, por ejemplo fíbulas: A Imagro y Torres, 1999). Este carácter elitista se vería fuertemente subrayado cuando junto a los equites equo publico aparecieron los equites equo priuato quienes, como signo de ostentación, mantienen un caballo aun sin disfrutar del aes hordearium². Un hecho que permite ver a los salios como infantes montados es el hecho de que éstos ejecutaban sus danzas a pie, y no a caballo. El escudo con forma de ocho, que se atribuye a modelos micénicos, recuerda el escudo denominado «tipo Dypilón», utilizado en Grecia en el periodo Geométrico, durante el cual se produjo la transición del ejército basado en la caballería pesada aristocrática al ejército hoplita, cuyo escudo redondo terminó por substituir al anterior (Greenhalgh, 1973: 64-67).

Esta reconstrucción, realizada principalmente a partir de datos de carácter literario y filológico, sin embargo, presenta problemas, ya que carecemos prácticamente de datos arqueológicos con anterioridad a la guerra de A níbal. Polibio (6.25) dice que recientemente (pero ¿qué tan recientemente?) la caballería romana había adquirido la cota de mallas y la lanza griegas y que antes iba armada más ligeramente. El armamento ligero la hacía más vulnerable pero, en cambio, dice expresamente que le permitía desmontar y montar con mayor agilidad. Este cambio, cuyo testimonio más antiguo es el monumento de L. Emilio Paulo en Delfos (168 a.C.), debería situarse inmediatamente después de la batalla de Cannas (216 a.C.) en la que la caballería romana fue aniquilada por la caballería númida, hispana y gala (M cCall, 2002).

Finalmente, en esta búsqueda de paralelos, podemos citar también la situación que César describe en las Galias (B.G., 6.13), hasta cierto punto comparable a la de Celtiberia por lo que se refiere al aspecto militar. César dice que había dos grupos preeminentes en la sociedad gala: el de los druidae y el de los equites, de tal manera que el resto de la población no contaba para nada. A unque en este caso no pueda establecerse un paralel o exacto, nuevamente vemos cómo la calificación militar (equites) coincidía con la calificación social (aristócratas).

Podemos intentar correlacionar los datos y las descripciones proporcionadas por los autores clásicos con la información arqueológica (Lorrio, 1993, 1994 y 1997).

L a existencia de un grupo socialmente privilegiado, reducido numéricamente y diferenciado mediante la posesión de una panoplia más completa que comprende lanzas con largas puntas de hasta $50 \mathrm{~cm}$ y regatones de gran longitud, cuchillos afalcatados y escudos, se documenta ya en la fase inicial de algunas necrópolis celtibéricas como las de Sigüenza, Valdenovillos, A tienza, Carratiermes, La M ercadera o Ayllón, repartidas entre los territorios del al to Duero y el al to Tajo-alto Jalón, que van a constituir el núcleo de la Celtiberia histórica. Esta fase inicial, datable en torno al siglo VI a.C., configura lo que A. Lorrio denomina fase I de la panoplia celtibérica (Lorrio, 1994: 216-221). D urante la fase II (siglos V y IV a.C.), coincidente con el apogeo de la cultura celtibérica, el armamento se amplía con la aparición de puntas de lanza pequeñas, que deben corresponder a jabalinas, que suelen depositarse en las tumbas en número de dos y a veces de tres ejemplares, soliferrea, lanzas semejantes al pilum, además de

2 M arín y Peña, 1956: 2-3 y 10-15, quien compara la primitiva caballería romana con un cuerpo de dragones; A dcock, 1963: 6 y 25; A Iföldi, 1965 y 1967; Ogilvie, 1981: 43-44, quien sugiere que el armamento de los salios perpetuaba el recuerdo de las armas y los métodos primitivos de combate. Este armamento estaba formado por un escudo en forma de ocho (ancila), un pectoral de bronce, un yelmo y una espada larga (Dionisio 2.70 ). 


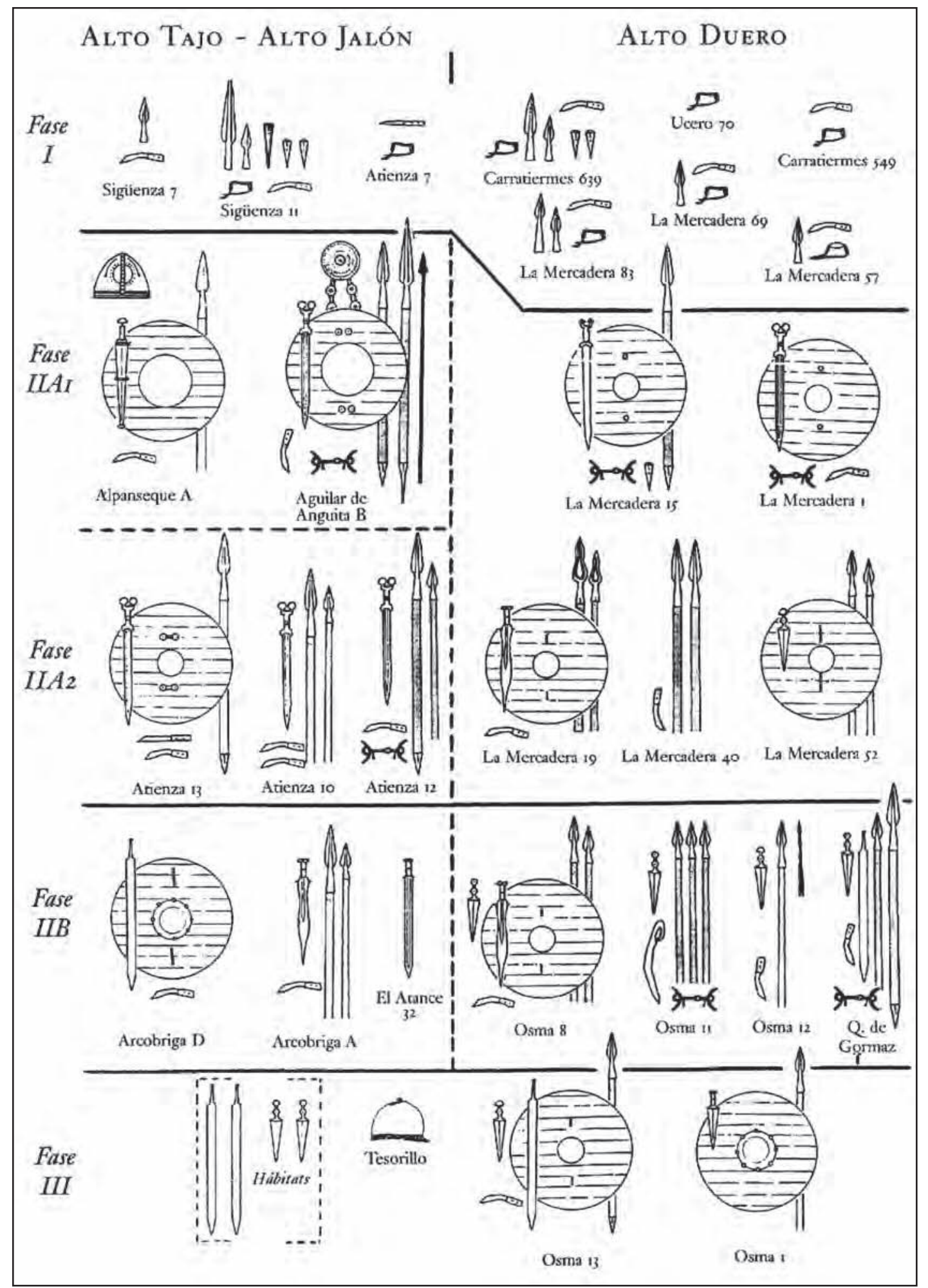

Figura 4. Evolución de la panoplia celtibérica (según Lorrio, 1997). 
las espadas de frontón y de antenas características de los celtíberos (L orrio, 1994: 221-226). L as tumbas más ricas de A guilar de A nguita y de A I panseque, correspondientes a este periodo, muestran además la presencia de discos-coraza de bronce y de cascos de este metal. Que este tipo de tumbas corresponde a una minoría social, evidentemente más rica que el resto, que concede especial importancia al uso del caballo, lo pone de manifiesto el hecho de que dichas tumbas suponen menos del $1 \%$ del conjunto de sus respectivas necrópolis, además del hecho de que en todas ellas abunden las piezas de atelaje de caballos (L orrio, 1994: 225).

A finales del siglo $\mathrm{V}$ y comienzos del siglo IV a.C. se produce una desaparición de importantes el ementos de prestigio que antes se depositaban en las tumbas, como los cascos, los discos-coraza y los umbos de bronce decorados. De ello no se puede deducir necesariamente una nivelación social y una pérdida de importancia de la caballería aristocrática, sino que puede corresponder a un cambio en las costumbres funerarias. L a necrópolis de A tienza, donde mejor se documenta esta subfase (IIA 2), muestra una presencia bastante nutrida de arreos de caballo, siempre en relación con tumbas que cabe considerar como «ricas» (Lorrio, 1994: 226). La panoplia muestra tres combinaciones diferentes: la que presenta el equipo más completo, con espada, una o dos lanzas, al gún regatón ocasional, y escudo; la que posee espada, una o dos lanzas y un regatón; y la que posee una, dos o tres puntas de lanza que suelen estar acompañadas de regatones. En todo caso, este armamento muestra la preferencia por un tipo de lucha con arma arrojadiza, quizás desde el caballo, dirimiéndose el combate a corta distancia y a pie con espada o cuchillo en caso de que el ataque con lanza no tuviese éxito.

El armamento celtibérico y la forma de combatir que pudieron observar los autores clásicos como Polibio, o sus informantes, y que describen el mismo Polibio, Posidonio, Diodoro o Estrabón correspondería a la fase III de la panoplia celtibérica, de acuerdo con la evolución propuesta por A. Lorrio (1997; 2002), que es la que corresponde a los siglos III-II a.C. LoS rasgos característicos de esta última fase son la tendencia a la uniformización de la panoplia, cuyos dos elementos fundamentales son la espada y, especialmente, el puñal biglobular. El problema que existe para la reconstrucción del armamento de este periodo es que desde comienzos del siglo III a.C. Ia presencia de armas en los ajuares funerarios de las necrópolis de la comarca del alto Tajo-alto Jalón se reduce considerablemente (Lorrio, 1994: 228-229; A Imagro y L orrio, 1991). Se ha interpretado este fenómeno como la consecuencia de una modificación en el valor ritual de los objetos depositados en las tumbas, pero creemos que deberían tenerse en cuenta también otros factores históricos, como la creciente presión cartaginesa sobre la M eseta y, desde las dos últimas décadas del siglo III, también la romana. Esta presión ha podido provocar un empobrecimiento del comercio y de los suministros del área celtibérica, obligando por necesidades prácticas a no amortizar el armamento en las sepulturas, lo cual se haría tanto más necesario ante el ambiente bélico creciente con la presencia en la M eseta de las dos potencias mediterráneas y, después, con el avance de la conquista romana. Creemos que es significativo que este fenómeno se aprecie menos en la zona del al to Duero, más alejada del litoral mediterráneo y de los escenarios del conflicto, donde necrópolis como las de Q uintanas de Gormaz y O sma presentan todavía armas, especialmente espadas y puñal es asociados en la misma tumba, como un comentario a Diodoro 5.33.

Otras fuentes susceptibles de ser utilizadas para este momento son las representaciones de guerreros celtibéricos que aparecen en al gunas cerámicas pintadas de 0 ceanilla o de N umancia (fig. 5). En dos pinturas numantinas que se interpretan como representaciones de guerreros muertos que están siendo devorados por buitres (nos. 1 y 2), los guerreros van armados con espadas cortas, probablemente del tipo de espadas con antenas atrofiadas. Otra pintura representa a un individuo que lleva una espada corta o un puñal biglobular al cinto. Otras dos (nos. 7 y 8) muestran personajes que llevan también espada corta, además de una especie de ramo en 


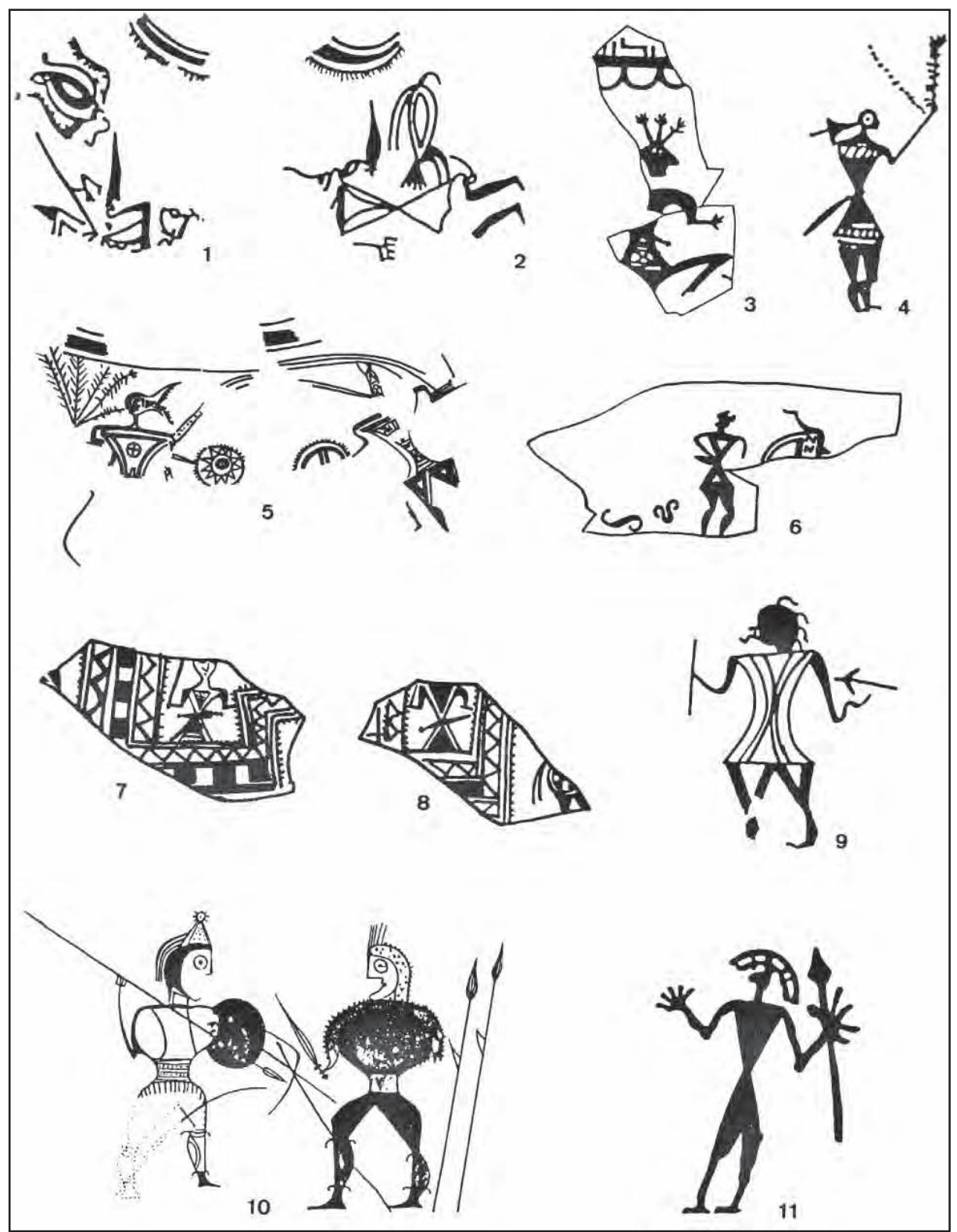

F igura 5. Imágenes de guerreros en cerámicas celtibéricas (según L orrio, 1997).

la mano. U na pintura de 0 ceanilla ( $n-9$ ) muestra un soldado armado de jabalina y escudo pequeño, verosímilmente una caetra; y otra ( $n-11$ ) muestra un guerrero con casco con penacho, como los aludidos por Estrabón, y una lanza o jabalina. Quizás la representación más completa del armamento celtibérico sea la que nos proporciona el denominado «vaso de los guerreros» de N umancia ( $n$ - 10). En él vemos a dos guerreros que se enfrentan en combate singular. A mbos parecen llevar cascos con penachos y ambos, especialmente el de la derecha, cuyo tórax relleno de color presenta un borde dentado o irregular como representando mechones, parecen llevar también corazas, tal vez de nervios. El de la izquierda empuña lanza y caetra, en la que parece que se ha clavado una jabalina que está doblada a consecuencia del impacto. EI de la 
derecha blande una espada corta y tras de él hay dos lanzas clavadas en el suelo por sus regatones esperando ser utilizadas. A mbos contendientes llevan también grebas o canilleras como las que citaba igual mente Estrabón.

Las representaciones de armas en las monedas también corresponden a este periodo. No obstante, en los casos en que son reconocibles, parecen obedecer a un interés más bien emblemático, ritual o de prestigio, que al interés de representar las armas que efectivamente se utilizaban en aquellos momentos (L orrio, 1995).

La asociación de arreos de caballo, principalmente en contextos funerarios, con los elementos más ricos o lujosos de la panoplia, y su presencia en un número minoritario de tumbas, muestran la relación entre el equipamiento de caballería y la élite social; lo que podríamos llamar una «aristocracia». En la necrópolis de A guilar de A nguita más de la mitad de las tumbas con espada, que son las tumbas de mayor riqueza, muestran arreos de caballo. Este mismo hecho sucede en A I panseque y Sigüenza. En la necrópolis de A tienza los arreos aparecen en tumbas cuyo ajuar consta de más de cinco elementos, es decir, en tumbas que podemos considerar de personas más ricas que pueden costearse un armamento más completo, hallándose particularmente estos arreos en las cuatro sepulturas con mayor número de objetos. En la necrópolis de Arcobriga, si bien los arreos son más escasos, aparecen significativamente en la sepultura B , que Cerral bo cree propia de un «jefe». En la necrópolis de L a M ercadera se hallaron 6 enterramientos con arreos, asociados con armas en todos los casos, cinco de los cuales pueden considerarse, según L orrio, como tumbas «ricas» (Lorrio, 1997; J imeno, 2004). También habría que considerar las estelas clunienses con representaciones de jinetes con caetra y, a veces, lanzas; dado el coste económico de la estela y lo singular de la representación, debemos considerar a estos individuos como aristócratas locales ( $M$ arco, 1975). También entre los vadinienses se observa la presencia de caballos en las estelas, a lo cual se ha atribuido un significado escatológico pero que, tal vez, podría guardar relación con un estatus aristocrático de los difuntos: tanto el coste económico como lo restringido de la práctica epigráfica parecen indicar que estas personas son los elementos más pudientes de la sociedad.

Si tenemos en cuenta los distintos tipos de fuentes, arqueológicas, literarias y vasculares, lo que parece más probable es la existencia de un armamento muy variado, resultado de las distintas situaciones socioeconómicas de cada guerrero en particular. D entro de esta situación, se observa una cierta homogeneización de la panoplia en la época coincidente con la conquista romana, centrada en la espada y el puñal, lo que respondería a la dispersión del puñal biglobular que se convierte en el arma corta más general del guerrero céltico peninsular.

L a importancia que asume la espada en este periodo puede observarse no sólo en el interés que los autores clásicos como Filón, Polibio, Suidas y otros muestran por su tipología y sus técnicas de fabricación (Pol. Fr. 96, en Suidas; L iv. 31.34.4), sino también por la existencia de al gunas referencias clásicas que parecen indicar que este arma, además, tendría un cierto valor simbólico. Durante la guerra de N umancia, Q . O ccio, legado de M etelo, sostuvo dos combates singulares. El primero fue contra un celtíbero que lo había desafiado y que se presentó montado a caballo. En el segundo, venció a un noble celtibérico de nombre Pirreso o Tiresio, «nobilitate ac uirtute omnes Celtiberos praestantem». Éste entregó al romano su espada y su ságulo a la vista de ambos ejércitos, mientras que el romano pidió que ambos se unieran mediante la ley de la hospitalidad cuando se restableciese la paz entre celtíberos y romanos: nec erubuit flagrantissimi pectoris iuuenis gladium ei suum et sagulum utroque exercitu spectante tradere, ille uero etiam petiit, ut hospitii iure inter se iuncti essent, quando inter Romanos et celtiberos pax foret restituta (Liv. Oxyrh. 164; Val. M ax. 3.2.21).

Es posible que en relación con este valor simbólico del arma, y en particular de la espada, esté un hecho bien atestiguado en el relato de las guerras de conquista, que es la resistencia de 
los indígenas a entregar las armas como símbolo de rendición. De hecho, el aspecto simbólico de la entrega de armas como reconocimiento de la derrota es una constante en la historia militar. Evidentemente, el desarme tiene una finalidad práctica, que es prevenir que el enemigo pueda volver a utilizar sus armas contra el vencedor, pero la resistencia de los indígenas a entregar las armas puede tener además un valor específicamente simbólico y no sólo práctico. En numerosos casos, observamos que, durante las negociaciones de paz, los indígenas aparecen dispuestos a acatar las condiciones impuestas por los romanos, que implican el reconocimiento de su derrota, excepto la entrega de las armas. A sí, en 139 a.C., cuando Popilo L enas reclamó las armas a los lusitanos, éstos retomaron la lucha: cum alia dedisset et arma peterentur, beIlum renouauit (D e U ir., 71). A piano (Ib., 31) cuenta lo mismo de unos celtíberos que durante la segunda guerra púnica combatían junto a A nnón: a requerimiento romano, entregaron a sus jefes, el campamento y dinero, pero cuando se les pidió las armas volvieron a combatir. Las fuentes literarias citan durante las guerras de mediados del siglo II a.C. numerosos casos en que los romanos exigieron las armas dentro de las negociaciones de los tratados de paz. En el año 153 a.C., N obilior se las exigió a los segedenses y numantinos que se le enfrentaron juntos. En el 143 a.C., Q. Pompeyo las exigió en Lagni y en Malia y, al año siguiente, también se las exigió a los numantinos que negociaban con él la paz. Finalmente, entre las condiciones que en el 133 a.C. Emiliano impuso a N umancia al rendirse, también estuvo la de que entregaran las armas. Por lo que respecta a la H ispania U Iterior, también se menciona la entrega de armas en el tratado del 152 a.C. suscrito entre M. A tilio y los lusitanos y vettones, y en el 150 en el tratado entre Galba y los lusitanos que era una continuación del anterior. En el 147, Vetilio les exigió igual mente las armas a los lusitanos, de lo que les previno Viriato. En el 139, como hemos dicho antes, Popilio L enas según unas fuentes a los lusitanos y, según otras, a los lusones. En el 139 Q. Servilio Cepión exigió también su entrega para hacer la paz a Tautalos, y en los años 138-136 a.C. D. Junio Bruto exigió las armas a los habitantes de Talabriga que querían rendirse.

A pesar de que la espada parece haber sido la pieza más importante de la panoplia durante la última fase de la evolución del armamento celtibérico, las fuentes literarias, sin embargo, insisten en señalar que las armas más extendidas y más frecuentemente usadas eran las arrojadizas. A sí, A piano (Ib., 51) dice que durante el ataque de L úculo a C auca se trabó un combate. L os caucenses, armados a la ligera, Ilevaron al comienzo la mejor parte, hasta que les faltaron los dardos; entonces se refugiaron en la ciudad ya que eran poco hábiles en la lucha de resistencia. Cuando los caucenses demandaron a Lúculo las condiciones de paz, éste les pidió que su cabal lería se uniese a los romanos. D urante el asedio de Intercatia, I os intercatienses tampoco eran capaces de presentar una batalla campal (Ib., 53). Por su parte, Lúculo hubo de levantar el asedio de Pallantia hostigado por la caballería, que le impedía aprovisionarse adecuadamente. Dicha caballería le hostigó hasta que logró cruzar el río Duero (Ib., 55). Verosímilmente, ésta era la élite del ejército de los palantinos.

A hora bien, cuando hablamos de una élite ecuestre de las ciudades, ¿de cuántos individuos estamos hablando exactamente?, puesto que para el concepto de élite el aspecto cuantitativo es fundamental. Si, como parece, hay que identificar aristocracia y calificación ecuestre militar, ¿podemos encontrar en las fuentes literarias datos que nos informen acerca de las dimensiones de dicha aristocracia dentro de las ciudades cel tibéricas? Si nos atenemos a lo que dicen dichas fuentes parece que esta aristocracia estaba formada por pocos indivíduos, lo que se correspondería con el hecho arqueológico de que las tumbas más ricas, especialmente las tumbas con arreos de caballo, son poco numerosas en las necrópolis celtibéricas. En Certima, Sempronio Graco exigió 40 nobiles equites (Liv. 40.47.10). En Alce, multi captiui nobiles in potestate uenerunt (Liv. 40.49.4), sin que se nos especifique realmente el número. En Nertobriga $\mathrm{M}$. 
Claudio M arcelo exigió 100 jinetes combatientes (hippéas systrateúsontas) (A p. Ib., 48). En Intercatia, Licinio Lúculo exigió 50 rehenes (pentékonta ándras es hómera) (A p. Ib., 54). Y en Numancia, ciudad no sólo más grande y más potente, sino donde se habían refugiado además los segedenses y probablemente tropas venidas de otras ciudades de celtiberia, Q. Pompeyo exigió tentativamente 300 rehenes (A pp. Ib., 79; Diod. 33.16). En todos estos casos vemos, además, la relación entre aristocracia y caballería ya que, lógicamente, hay que esperar que los rehenes exigidos por los romanos fuesen no sólo los mejores elementos desde el punto de vista militar, sino además que perteneciesen a las mejores familias, 0 a aquellas gobernantes, a fin de garantizar de esta manera el cumplimiento de lo tratado.

La manera de combatir de dicha aristocracia puede reconstruirse también a partir de los relatos literarios. Por supuesto, la utilización de dichos textos debe hacerse con una gran precaución, dado el elemento retórico que impregna todas estas narraciones. Esto último es especialmente importante en el caso de Tito Livio, utilizado por A piano junto con Polibio, y cuyos datos muchas veces son deudores de los de los analistas. Pero no deja de ser significativo, en nuestra opinión, que los casos en que la información es más precisa o parece más fiable, pertenecen casi todos a la guerra numantina, de la cual Polibio fue testigo ocular o, en todo caso, tuvo buena información. De acuerdo con lo que dicen dichas fuentes, parece que la manera de combatir preferida de la aristocracia era la de combates singulares entre campeones. D urante el sitio de Intercatia por Lúculo, se presentó un bárbaro desafiando a los romanos a un combate singular. A piano (I b., 53) dice que iba vestido con armas resplandecientes y que ninguno de los romanos se atrevía a enfrentársele, con el consiguiente escarnio público por parte del celtíbero. Hasta que Escipión, que todavía era muy joven, reclamó sus armas y su caballo y, a pesar de ser poco corpulento, lo venció y lo mató. De la descripción de A piano se sigue que el combate entre ambos debió ser un combate ecuestre, seguido de una lucha a pie en la que venció Escipión (¿con espada?). Polibio, fr. 35, 5, da el detalle de que el caballo de Escipión fue herido, pero éste no cayó al suelo, sino que saltó recto a tierra. De este detalle se deduce que Polibio, que fue probablemente testigo presencial ya que acompañaba a Emiliano durante la campaña de Lúculo, es la fuente tanto de A piano como de la periocha 48 de Livio, que también narra este suceso. Lo importante es observar que este individuo de armas resplandecientes debía ser un aristócrata. Su estatus social el evado se puede deducir también del hecho de que un hijo del vencido firmaba con un sello con la imagen de aquella lucha, citando Plinio la ocurrencia de Estilón Preconino de qué no hubiera hecho dicho individuo si en vez de haber muerto hubiera sido su padre quien hubiese vencido a Escipión (Plin. Nat., 37.9). Es de suponer que la práctica de firmar con sello (probablemente un anillo) en la sociedad celtibérica, lo mismo que en la romana, se daba sobre todo entre miembros de la aristocracia.

Conocemos otros dos combates singulares, acaecidos durante la campaña de Q. Cecilio $M$ etel o contra los celtíberos. Su legado, Q . Occio, como hemos dicho anteriormente, libró primero uno contra un joven celtíbero que lo había desafiado y se presentó al combate montado a caballo; y, luego, libró otro contra un tal Pirreso o Tiresio que era «sobresaliente en nobleza y valor entre todos los celtíberos» según Valerio M áximo, lo que parece indicar que en ambos casos se trataba de miembros de la aristocracia indígena. Las dos formas del nombre: Pyrresus (Val. M ax.) y Tyresius (Liv.), deben ser formas corruptas. M. L. A lbertos (1966: 188 y 241) creía que la variante Tyresius que da Tito Livio encaja mejor en la antroponimia hispana. La verdadera lectura podría ser Turesus o Turesius. El primero aparece en Germania inferior, CIL, X III, 8066. Formas como Turos y derivados de él como Turaeus, Turovius, etc., se documentan ampliamente en H ispania (Untermann, 1965:177-178 mapa 78: Turaius).

Tenemos igual mente un objeto arqueológico, al menos, que escenifica esta forma de combatir. Es el denominado «vaso de los guerreros» de Numancia (Taracena, 1976: 286 fig. 174; 
A rgente et alii s.a.: 147 fig. 162; Romero, 1976). Se trata de una cerámica con decoración pintada polícroma que debe datarse probablemente en el siglo I a.C. (figs. 6 y 7). Es decir, que es posterior a la época de las guerras de conquista a que nos referimos. La pintura presenta una serie de escenas inconexas, que aparentemente no tienen relación entre sí. El motivo más importante, por el espacio que se le dedica, es el combate singular entre dos guerreros a pie. Hacia la izquierda, hay dos especies de grifos afrontados y, a continuación, dos caballos fantásticos ¿con colas de grifos?, también afrontados, entre los cuales, y un poco hacia abajo, surge la representación de un ave sobre una especie de nido con dos huevos. El carácter inconexo y aparentemente absurdo de estas escenas podría deberse al hecho de que estén representando al gún mito o relato tradicional celtibérico, subsistente bajo la conquista romana, cuyas claves interpretativas se han perdido para nosotros (H att, 1981; Salinas, 1994; A Ifayé, 2003; C urchin, 2004-2005). El armamento de los guerreros, como hemos dicho antes, parece corresponder al armamento que según Estrabón correspondería a los combatientes más ricos: casco con penacho, coraza, grebas, escudo redondo, espada y lanza o jabalinas. El guerrero de la derecha parece haber utilizado ya su lanza, que se ha doblado sobre el escudo de su adversario, y ha echado mano de la espada a pesar de que tras de sí parece conservar todavía dos lanzas disponibles, clavadas por en regatón en el suelo. El otro guerrero, por su parte, blande su lanza en el aire, dispuesto a arrojarla.

Por consiguiente, tenemos un conjunto de fuentes, literarias y arqueológicas, que parecen indicar de manera bastante evidente que la tropa de élite de las ciudades celtibéricas era una

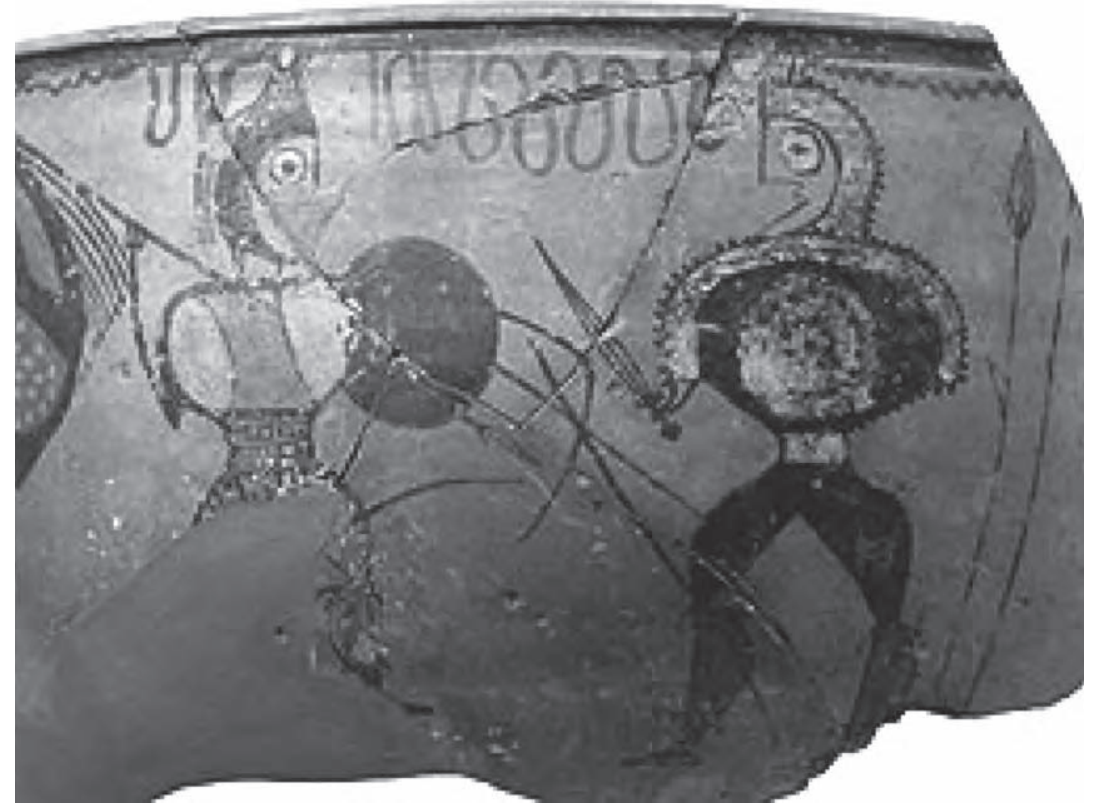

Figura 6. Vaso de los guerreros, Numancia (según Romero, 1976).

infantería montada, armada como hoplitas, que en caso necesario desmontaba, dejando los caballos en formación, y combatía como infantes. En los combates singulares iniciarían el ataque a caballo y con lanzas o jabalinas, continuando el duelo a pie y con espada si el caballo caía. Esta caballería aristocrática constituía la fuerza más importante de las ciudades-estado de la 


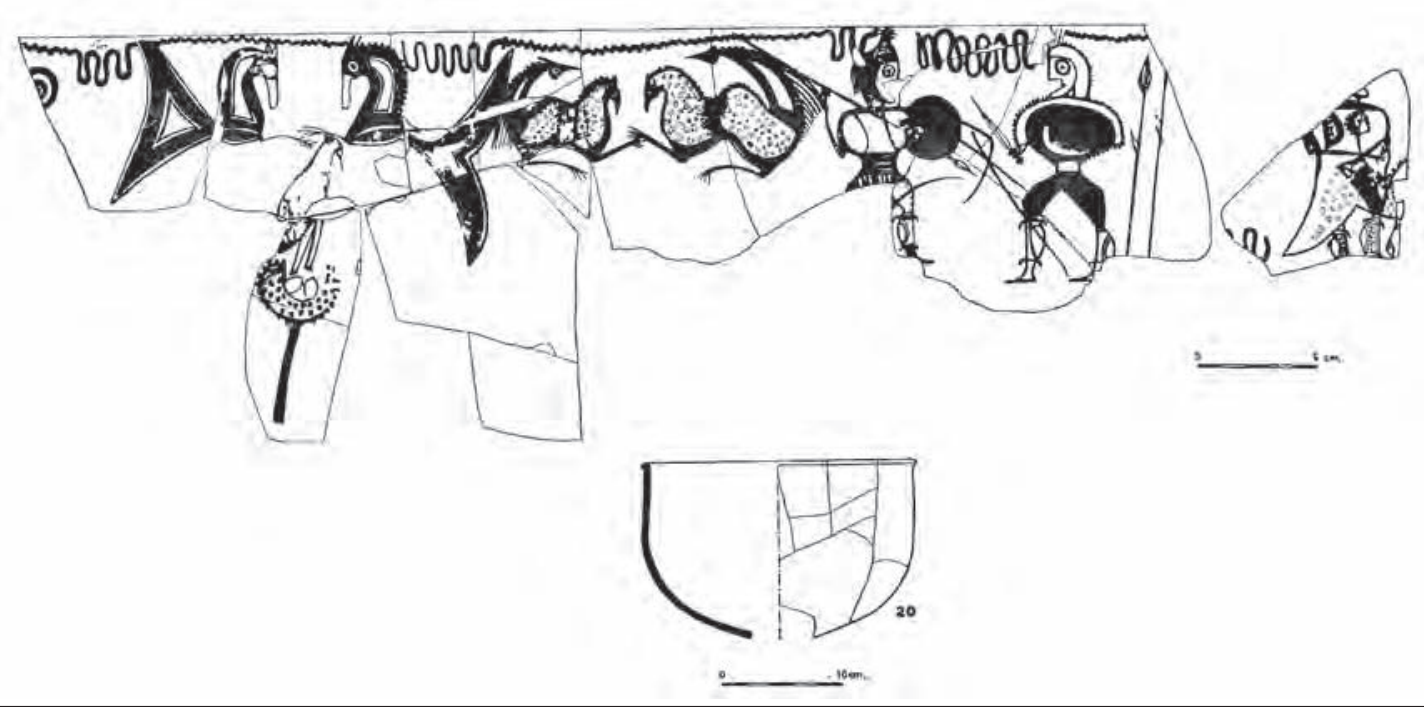

Figura 7. Desarrollo del vaso de los guerreros (según Romero, 1976).

meseta central hispana, no por su número, que por lo general parece que era restringido, sino por cumplir el papel decisivo en las batallas, en las cuales combatía mezclada con los infantes, tal como dice Estrabón. Podemos suponer, además, que entre dichos infantes estaban quienes se vinculaban a los miembros de la aristocracia mediante vínculos de deuotio y clientela, y que la posesión de séquitos militares más o menos amplios era la manifestación evidente de mayor o menor influencia social.

Creemos que es en relación con la existencia de la clientela militar y de la deuotio con lo que hemos de poner el texto citado al principio (Str. 3.4.18), según el cual no era exclusivo de los iberes que dos hombres fueran montados en el mismo caballo, y que uno de ellos en el combate luchara a pie. En el comentario a este pasaje, Schulten comparaba esta costumbre con otra de los germanos, atestiguada por César (B.G., 1.47), Tácito (Germ., 6), A miano M arcelino (16.12.21), Livio (44.26) y Plutarco (E mil. Paul., 12), según la cual cada caballero germano Ilevaba a su lado un infante que lo acompañaba corriendo pero sin subir a caballo, como era costumbre entre los hispanos. Estos infantes les socorrían si eran heridos o derribados del caballo. Entre los germanos tales infantes eran seleccionados privadamente por los propios jinetes y podemos suponer que en la península I bérica sucedía algo parecido. A mbas prácticas deben ser la expresión de una relación determinada de clientela y podemos recordar, en este caso, que los textos que se refieren a la deuotio ibérica dicen que era nefasto para los devotos o soldurios sobrevivir a sus jefes si morían en combate (Plut. Sert. 14; Serv. Ad G eorg., 4.218; Val. M ax. 2.6.11; Caes. B.G., 3.22; Str. 3.4.18).

Su papel decisivo en la guerra prerromana se quebró frente al ejército romano, cuya sólida formación de infantes, disciplinada y uniformada en el armamento, ofrecía una barrera infranqueable a las tropas indígenas. Polibio-A piano dice que los ejércitos celtibéricos eran buenos en el primer choque, pero que no podían sostener un combate continuado. La lectura de las fuentes literarias muestra que la guerra celtibérica es una guerra de asedios principalmente.

L a única batalla campal que se narra, la del 23 de agosto del 153 a.C., registra la victoria de los celtíberos debida a una emboscada; pero, cuando los celtíberos se lanzaron en persecución de los romanos, la caballería de Nobilior los atacó y mató a Caro, y ninguno de los contendientes puso imponerse al otro, hasta que la noche los separó (A pp. Ib., 45). Tres días después 
se enfrentó a los celtíberos bajo los muros de Numancia. A I principio, la batalla fue favorable a los romanos, principalmente gracias al uso de diez elefantes que había enviado M asinisa y que los hispanos veían por primera vez. Pero cuando uno de los el efantes recibió la herida de una piedra, se volvió contra los propios romanos, desbaratándolos y ocasionando su huida perseguidos por los numantinos (Ib., 46). D espués N obilior intentó tomar la ciudad de Axinio, sin conseguirlo; y las fuerzas que venían en su ayuda fueron atacadas nuevamente en una emboscada (I b., 47). A I año siguiente, cuando Claudio M arcelo se dirigió contra N umancia, dice A piano otra vez que los celtíberos pretendieron tenderle otra emboscada (Ib., 48). M ientras negociaba con los nertobrigenses, algunos de ellos atacaron la retaguardia romana. A piano especifica que eran jinetes (Ib., 48). No hubo batalla contra ellos, sino que M arcelo procedió al asedio de la ciudad, levantando vallas y acercando máquinas (Ib., 49). Cuando nuevamente reemprendió las hostilidades contra Numancia, I os numantinos no ofrecieron batalla en campo abierto, sino que se encerraron en la ciudad (Ib., 50). Durante la campaña de Cecilio M etelo en los años 143-142 a.C., se menciona el asedio de Centobriga utilizando catapultas, a cuyos tiros se expusieron a los hijos del celtíbero Retógenes, que se había pasado a los romanos (Val. M ax. 5.1.5; Oxyrh. 160). Sí se sabe que hubo lucha para tomar la ciudad de Contrebia, pero los datos de las fuentes son anecdóticos y no permiten saber si fue una batalla campal o parte del asedio (D e vir., 3.61; Val. M ax. 2.7.10 y 7.4.5; Vel. Pat. 2.5.2; etc.). De nuevo, durante la campaña de Pompeyo (141 a.C.) éste acampó frente a N umancia. A piano (Ib., 76) dice que ambos ejércitos formaron en la Ilanura, pero que los numantinos al poco emprendieron la huida y que entonces los romanos, persiguiéndolos, cayeron en fosos y en trampas. A este enfrentamiento siguieron otros que A piano califica de «escaramuzas» (I lb., 77). Dirigiéndose entonces contra Tiermes, en un mismo día hubo tres choques entre el ejército romano y los celtíberos en campo abierto, hasta que final mente los romanos quedaron acorralados en un lugar escarpado, desde el que muchos se despeñaron, muriendo. Después de estos fracasos se dirigió contra Lagni, donde había una guarnición numantina, y aprovechando las discordias internas durante el cerco, tomó la ciudad (Diod. 33.17). También durante el invierno muchos romanos murieron en emboscadas cuando salían por leña y por provisiones del campamento (I b., 78). Paradigma de las emboscadas es la que los numantinos le tendieron al cónsul M ancino en el año 137 a.C., en la que el cónsul se vio obligado a capitular y a negociar una paz sobre las leyes de los celtíberos al ser sorprendido mientras huía de noche y confinado en un lugar sin fortificaciones, sin fuego y sin comida (Ib., 80; Plut. Tib. G raco, 5; de vir., 3.59). Su sucesor, E milio L épido, atacó ilegalmente a los palantinos. El ataque consistió en un cerco, obstaculizado por las habituales emboscadas contra las provisiones, que al prolongarse puso a los romanos al borde del desastre. Final mente, Lépido se retiró por la noche, abandonando a los soldados enfermos y heridos, y si los palantinos no aprovecharon mejor la ocasión, en opinión de A piano, es porque alguna divinidad se lo inspiró (Ib., 80-83). Finalmente, y como es bien sabido, la victoria final romana se debería al completo cerco de N umancia trazado por Escipión Emiliano (Ib., 90-92). Como podemos ver, las victorias del ejército celtibérico se debieron sobre todo a tres factores: al mejor conocimiento y aprovechamiento estratégico del terreno, a la inexperiencia del ejército romano, y a la superioridad numérica de los indígenas.

Quesada (2006: 160-167) ha comparado el texto de A piano referente a la batalla de las Vulcanalia del 153 a.C. con la descripción de la batalla de Trebia, en que A níbal venció a los romanos mediante una emboscada o ataque por sorpresa, para sostener que los ejércitos celtibéricos estaban similarmente organizados a los ejércitos que consideramos más avanzados, cartagineses y romanos. I gualmente cita dos batallas sucedidas durante la segunda Guerra Púnica, en que tropas celtibéricas con armamento pesado u hoplítico, que combatían bajo el mando de los cartagineses, actuaron de manera organizada y regular tanto al recibir el ataque 
como al contestar al mismo mediante lanzas y espadas (año 207 a.C.: Liv. 28.1.7-8; año 203 a.C: Polib. 14.7.5-7). En nuestra opinión la comparación entre la batalla de Trebia y la del 23 de agosto del 153 a.C. no presenta más que una semejanza superficial, desde el momento en que la astucia y el factor sorpresa son elementos fundamentales de la estrategia militar utilizados por ejércitos poco o mucho organizados. Desde luego, el ejército celtibérico no debía ser una horda inconexa como podría hacer ver una visión primitivista de su sociedad. En el momento de la guerra contra Roma, los celtíberos formaban una coalición militar compleja, dentro de la cual los arévacos eran el elemento más poderoso, con guarniciones en plazas estratégicas que servían para garantizar la fidelidad de sus aliados y la cohesión de la alianza (Salinas, 1996: 99-103; 2006: 117-121; en la actualidad creo que hay que verlo más como una confederación de ciudades y no de «tribus», aunque el elemento étnico no parece haber estado ausente). Hay que suponer que efectivos tan cuantiosos como los que menciona A piano, 25.000 combatientes, tuviesen una organización, ya que de lo contrario su propio número habría actuado en su contra.

Los testimonios de celtíberos combatiendo en el ejército cartaginés, sin embargo, deben ser mirados con mucha desconfianza. El testimonio más fiable a este respecto es la inscripción de A níbal dejada en el cabo Lacinio, que transmite Polibio, en la cual el general cartaginés enumeraba las tropas con que se replegó a Á frica. En dicha relación los celtíberos no figuran, como deberían haberlo hecho si hubieran formado parte de las fuerzas cartaginesas. Como hemos mostrado en otro lugar (Salinas, 2007: 38-393), Ias referencias tempranas a celtíberos, generalmente adversas a los mismos, como su participación en la muerte de Publio y Cneo Escipión o su dudosa fidelidad combatiendo bajo los turdetanos durante la campaña de Catón, parecen ser fruto de una reelaboración tardía, hecha probablemente en el transcurso de la guerra numantina, tendente a presentar bajo un cariz desfavorable a los que eran en ese momento los enemigos más temidos por los romanos, y a presentar la guerra contra ellos como una empresa familiar de los Escipiones.

No es discutible la capacidad celtibérica para combatir en batallas campales. Por desgracia, solo tenemos información de las guerras de estos pueblos contra Roma, una estructura política y militar mucha más compleja y muy superior a ellos, pero carecemos de noticias acerca de guerras, batallas y combates entre estos pueblos. Lo que parece deducirse del registro arqueológico, especialmente de los ajuares funerarios, e iconográfico, así como de las fuentes literarias que hablan de la existencia de una minoría de guerreros que llevaban panoplia completa e iban al combate montados a caballo (y a veces combatían sobre él, recuérdese el duelo de Escipión y el celtíbero) es que antes de trabar contacto con los ejércitos cartaginés y romano las luchas entre los pueblos indígenas debieron resolverse sobretodo por la actuación de esta infantería montada de carácter aristocrático, quizás muchas veces mediante duelos entre campeones. Dicha manera de combatir, evidentemente, se reveló ineficaz frente al ejército romano.

L a guerra es una actividad en la que se dan innovaciones muy rápidamente, ya que la propia vida está en juego. Por ello, no es descartar que los ejércitos indígenas adoptaran pronto formas de combatir de los romanos, con mayor organización y peso específico de la infantería. Por desgracia para ellos, los indígenas no escribieron la Historia, de manera que sólo tenemos atestiguados los cambios en sentido contrario. L os casos más citados son la adopción por los romanos de la espada de antenas celtibérica, el gladius hispaniensis, o las disposiciones de Emiliano durante las operaciones contra Numancia para colocar a sus soldados en una posi-

3 Sobre la ambigüedad del concepto de «Celtiberia» y de «celtíberos»: Salinas, 1988; idem, 2007: 39; Capalvo, 1996: 13-14, 19-20 et passim. 
ción competitiva con los celtíberos, obligándoles a vestirse y a comer como éstos. A lgunos detalles de la táctica de la caballería también pudieron ser utilizados. Hay un pasaje de difícil comprensión que quizás haga referencia a ello. Cuando en el año 180 a.C. Q. Fulvio Flaco regresaba de Celtiberia a Tarragona para entregar el mando a su sucesor, Sempronio Graco, los celtíberos le tendieron una emboscada en el M oncayo. Durante el combate, la situación se hizo extremamente apurada para los romanos, quienes solamente lograron vencer gracias a la caballería, después de que el pretor diera la orden: duplícate turmas! Como consecuencia de esta victoria, debida a la caballería romana, Flaco consagró en Roma un templo a la Fortuna Ecuestre. El comentarista de Livio en este punto dice ignorar qué clase de maniobra pudieron realizar entonces los equites romanos, pero si tenemos en cuenta tanto los precedentes de la táctica ecuestre en la propia Roma, como la práctica de los celtíberos atestiguada por Estrabón, a la que nos referíamos al comienzo, podría suponerse qué los jinetes romanos desmontaron y combatieron junto con los infantes, cerrando filas, y que a ello se debió la victoria.

\section{BIBLIOGRAFÍA}

A dcock, F. E. (1963): The Roman Art of War under the Republic. Cambridge (1940, reimp.).

A lbertos, M. L. (1966): La onomástica primitiva de Hispania. Tarraconense y Bética. Salamanca.

A lfayé, S. (2003): «L a iconografía divina en Celtiberia. Una revisión crítica». AE spA, 76: 77-96.

A Iföldi, A . (1967): «Die Herrschaft der Reiterei in Griechenland und Rom nach dem Sturz der Könige» Gestalt uns G eschichte. Festschrift K. Schefold, Bern.

Alföldi, A . (1965): Early Rome and the Latins, A nn A rbor.

A Imagro, M . y L orrio, A. (1991): «L es celtes de la péninsule I bérique au IIIe siècle avant J .-C.». Études Celtiques, XXVIII: 33-46.

A Imagro, M . y Torres, M . (1999): Las fíbulas de jinete y de caballito. Aproximación a las élites ecuestres y su expansión en la Hispania céltica. Zaragoza.

A rgente, J. L. et alii (s.a.): M useo Numantino. Guía del Museo. Soria.

Capalvo, A . (1996): Celtiberia. U n estudio de fuentes literarias antiguas. Zaragoza.

Curchin, L. (2004-2005): «M itología celtibérica: el problema de las bestias fantásticas». Kalathos, 2223: 183-193.

Greenhal gh, P. A . L. (1973): Early G reek Warfare. Horsemen and chariots in the Homeric and archaic ages. Cambridge.

Hatt, J. J. (1981): «Images indigènes et images gréco-romaines dans l'expression des conceptions religieuses celtiques», M éthodologie iconographique. Actes du colloque de Strasbourg. Estrasburgo: 59-62.

Hel big, W. (1904): «L es hippeis athéniens». M émoires de l'Institut National de F rance, 37/1: 157-sq.

Jimeno, A et alii (2004): La necrópolis celtibérica de Numancia. M emorias. A rqueología en Castilla y León, 12. Salamanca.

Lazenby, J. F. (1985): The Spartan Army. Warminster.

Lorrio, A . (1993) «El armamento de los celtas hispanos», Los celtas: Hispania y E uropa. M adrid: 285-326.

Lorrio, A . (1994): «L a evolución de la panoplia celtibérica». M D AI (M ), 35: 212-243.

Lorrio, A . (1995): «El armamento de los celtíberos a través de la iconografía monetal», M . P. GarcíaBellido y M. R. Sobral Centeno (ed.), La moneda Hispánica. Ciudad y territorio. Actas del I Encuentro Peninsular de Numismática Antigua (CSIC, M adrid 1994). A nejos del A rchivo español de A rqueología, XIV, M adrid, CSIC Sociedade Portuguesa de Numismática: 75-80.

Lorrio, A . (1997): Los celtíberos, A licante.

McCall, J. B., The Cavalry of the Roman Republic. Cavalry Combat and Elite Reputations in the Middle and Late Republic, Londres y Nueva York, 2002.

M arín Y Peña, J. (1956): Instituciones militares romanas. M adrid.

M arco Simón, F. (1975): Las estelas decoradas de los conventos caesaraugustano y cluniense. Zaragoza.

Ogilvie, R. M. (1981): Roma Antigua y los etruscos. M adrid (ed. inglesa 1976). 
Quesada Sanz, F. (1998): «A ristócratas a caballo: la existencia de una verdadera caballería en la cultura ibérica: dos debates conceptual es diferentes», C. A ranegui (ed.), Actas del C ongreso internacional Los iberos, príncipes de 0 ccidente. Barcelona: 169-183.

Quesada Sanz, F. (2006): «N ot so different: individual fighting techniques and battle tactics of Roman and Iberian armies within the Framework of warfare in the Hellenistic A ge», P. François, P. M oret $y$ S. Pérè N oguès (eds.), L'H ellénisation en mediter ranée occidentale au temps des guerres puniques. Pallas, 70. Toulouse: 245-263.

Quesada Sanz, F. (2006): «L os celtíberos y la guerra: tácticas, cuerpos, efectivos y bajas. Un análisis a partir de la campaña del 153» F. Burillo (coord.) Segeda y su contexto histórico. Entre Catón y Nobilior. Zaragoza: 149-167.

Romero Carnicero, F. (1976): Las cerámicas polícromas de Numancia. Soria.

Salinas, M. (1988): "Geografía de Celtiberia según las fuentes literarias griegas y latinas». Studia Zamorensia, IX: 107-115.

Salinas, M . (1994): «El toro, los peces y la serpiente» Homenaje a J .M. Blázquez II. M adrid: 509-519.

Salinas, M. (1996): Conquista y romanización de Celtiberia. Salamanca.

Salinas, M . (1998): «Sobre la caballería de los celtíberos en relación con su organización social». Hispania Antiqua, XXII: 75-88.

Salinas, M. (2005): «L as guerras celtibéricas». Celtíberos. Tras la estela de Numancia. Soria: 427-433.

Salinas, M. (2006): Los pueblos prerromanos de la península I bérica. M adrid.

Salinas, M . (2007): «L as guerras celtibéricas y la conquista romana del valle del Duero», M . Navarro Caballero y J. J. Palao Vicente (eds.), Villes et territoires dans le bassin du D ouro à l'époque romaine. Burdeos: 27-42.

Salinas, M . (2007): «Violencia contra los enemigos: los casos de Cartago y Numancia», G. B ravo y R. González Salinero (eds.), F ormas y usos de la violencia en el mundo romano. M adrid.

Taracena, B. (1976): «L os pueblos celtibéricos», Historia de España M enéndez Pidal, tomo 1, vol. 3. M adrid: 195-299.

Untermann, J. (1965): Elementos de un atlas antroponímico de la Hispania antigua. M adrid.

Recibido: 01/07/2009

A ceptado: $12 / 04 / 2010$ 